Agro Ekonomi Vol. 24/No. 1 Juni 2014

\title{
PERAN KELOMPOK TANI DALAM PENERAPAN SRI (SYSTEM OF RICE INTENSIFICATION) DI KECAMATAN KALIKAJAR KABUPATEN WONOSOBO
}

\section{The Role of Farmer Group in The Application of SRI (System of Rice Intensification) in Kalikajar Subdistrict Wonosobo Regency}

\author{
Chindra Yenni Wastika ${ }^{1)}$, Sunarru Samsi Hariadi ${ }^{2)}$, Subejo $^{2)}$ \\ 1) Jurusan Sosial Ekonomi Pertanian Fakultas Pertanian Universitas Gadjah Mada \\ ${ }^{2)}$ Fakultas Pertanian Universitas Gadjah Mada
}

\begin{abstract}
This research was conducted in Kalikajar Sub District Wonosobo Regency. The purpose of this research were to understand how far the role of farmer group in the application of SRI (System of Rice Intensification), influencing the factors in the role of farmer group in SRI application, and to understand the influence of the farmer group's role in the SRI application in Kalikajar Sub Wonosobo Regency. The method were used in this research was descriptive analysis. The data were analyzed by proportion test, multiple linear regression analysis and simple linear regression analysis.

The result of this research showed that more than $50 \%$ at sample evaluated that using rates the role of farmer group in high category. Farmer's attitude and the role of extension agents positively affected to the role of farmer group in SRI application. The farmer's level of education, land scale, farmer's experience, frequence of the attendance, and the role of farmer group's leader have no affect in the role of farmer group in SRI application. The role of farmer group as learning media, cooperation media, and production unit has positively affected to SRI application in Kalikajar Sub District Wonosobo Regency which means the application of SRI increased as the increased of the role farmer group.
\end{abstract}

Keyword: Farmer Group, The Role of Farmer Group, SRI, Kalikajar.

\section{INTISARI}

Penelitian ini dilakukan di Kecamatan Kalikajar Kabupaten Wonosobo dengan tujuan untuk mengetahui sejauh mana peran kelompok tani dalam penerapan SRI (System of Rice Intensification), faktor-faktor yang mempengaruhi peran kelompok tani dalam penerapan SRI, dan untuk mengetahui pengaruh peran kelompok tani terhadap penerapan SRI di Kecamatan Kalikajar Kabupaten Wonosobo. Metode penelitian yang digunakan adalah metode deskriptif analitik. Data dianalisis dengan uji proporsi, analisis regresi linear berganda dan analisis regresi linier sederhana.

Hasil penelitian menunjukkan bahwa lebih dari $50 \%$ petani menilai peran kelompok tani dalam kategori tinggi. Faktor yang berpengarung secara nyata adalah sikap dan peran penyuluh. Pendidikan petani, luas lahan, pengalaman petani, frekuensi kehadiran, dan peran ketua kelompok tani tidak berpengaruh terhadap peran kelompok tani dalam penerapan SRI. Peran kelompok tani berpengaruh positif terhadap penerapan SRI di Kecamatan Kalikajar Kabupaten Wonosobo yang berarti semakin tinggi peran kelompok tani maka semakin tinggi penerapan SRI.

Kata kunci: Kelompok Tani, Peran Kelompok Tani, SRI, Kalikajar.

\section{PENDAHULUAN}

Padi adalah salah satu tanaman pangan yang terus dibudidayakan secara intensif oleh kebanyakan petani Indonesia dan selalu dijaga ketersediannya. Oleh sebab itu pemerintah memberi perhatian lebih pada budidaya padi. Upaya pemerintah untuk mendukung produktivitas pertanian tanaman pangan telah diaplikasikan dalam berbagai inovasi baru salah satunya adalah melalui pendekatan SRI (System of Rice Intensification). Dalam pelaksanaan program SRI dibutuhkan partisipasi aktif petani agar seluruh prinsip-prinsip SRI sampai pada petani. Proses penyebaran dan penerapan SRI pada umumnya dilaksanakan melalui kelompok tani. Kelompok tani diharapkan dapat memainkan perannya dengan baik sehingga tujuan dari kelompok dapat dilaksanakan dengan efektif.

Tujuan dari penelitian yang akan dilakukan adalah untuk mengetahui sejauh mana peranan kelompok tani dalam penerapan SRI, faktorfaktor yang mempengaruhi peran kelompok tani dalam penerapan SRI, dan mengetahui pengaruh peran kelompok tani terhadap penerapan SRI di Kecamatan Kalikajar, Kabupaten Wonosobo. 


\section{TINJAUAN PUSTAKA}

\section{Kelompok Tani}

Kelompok dapat digunakan sebagai wadah bagi orang-orang yang memiliki keterikatan, nasib, dan tujuan yang sama. Definisi dari kelompok tani menurut Nasir (1997) dalam Dwiyanto (2010) merupakan kumpulan petani yang tumbuh berdasarkan keakraban, dan keserasian, serta kesamaan kepentingan dalam memanfaatkan sumber daya pertanian untuk bekerja sama meningkatkan produktivitas usaha tani dan kesejahteraan anggotanya. Adanya Kelompok tani diharapkan petani dapat saling bertemu dan bermusyawarah secara bersamasama untuk merencanakan suatu kegiatan. Wujud dari kegiatan kelompok tani bisa dicerminkan adanya pertemuan anggota kelompok secara rutin dan kegiatan gotong royong.

\section{Peran Kelompok Tani}

Peraturan Menteri Pertanian Nomor: 273/KPTS/OT.160/4/ 2007 Tahun 2007 kelompok tani memiliki beberapa fungsi, pertama sebagai kelas belajar guna meningkatkan pengetahuan, ketrampilan, dan sikap (PKS) sehingga tumbuh kemandirian, meningkatnya produktivitas, dengan harapan mencapai kesejahteraan. Fungsi yang kedua yaitu sebagai wahana kerjasama merupakan tempat untuk memperkuat kerjasama diantara sesama petani dalam kelompoktani dan antar kelompok tani serta dengan pihak lain. Melalui kerjasama ini diharapkan usaha taninya akan lebih efisien serta lebih mampu menghadapi ancaman, tantangan, hambatan dan gangguan. Kelompok tani sebagai unit produksi adalah fungsi selanjutnya dimaksudkan kelompok tani secara keseluruhan dipandang sebagai satu kesatuan usaha yang dapat dikembangkan untuk mencapai skala ekonomi, baik dipandang dari segi kuantitas, kualitas maupun kontinuitas dari usahatani yang dilaksanakan oleh masing-masing anggota kelompok tani.

\section{Penerapan Teknologi}

Penerapan adalah perbuatan mempraktekkan suatu teori atau metode untuk mencapai tujuan tertentu. Menurut Suprapto \& Fahrianoor (2004) dalam Ishak \& Afrizon (2011) adanya inovasi teknologi tidak serta merta diterapkan oleh petani melainkan melalui proses sampai petani benar-benar menerapkan inovasi tersebut. Adopsi petani terhadap teknologi pertanian sangat ditentukan dengan kebutuhan akan teknologi tersebut dan kesesuaian teknologi dengan kondisi biofisik dan sosial budaya. Oleh karena itu, introduksi suatu inovasi teknologi baru harus disesuaikan dengan kondisi spesifik lokasi.

\section{Faktor-Faktor yang Mempengaruhi Peranan Kelompok Tani dan Adopsi Inovasi}

Menurut Gerungan (1981) dalam Widyaningrum (2001) beberapa faktor yang memegang peranan terhadap perubahan sikap terhadap teknologi baru adalah:

a) Faktor internal, yaitu faktor yang terdapat pada diri pribadi manusia meliputi umur petani, status sosial ekonomi petani, pola hubungan petani, sikap terhadap perubahan, resiko, keinginan serta aspirasi petani.

b) Faktor eksternal, yaitu faktor yang terdapat di luar diri pribadi manusia meliputi sifat keuntungan relatif dari teknologi baru, gencarnya kegiatan penyuluhan oleh PPL atau kelompok tani, ciri-ciri sistem sosial masyarakat dimana petani menjadi anggotanya (masyarakat modern dan tradisional), saluran komunikasi yang digunakan, adanya tekanan, perintah atau pelaksanaan penguasa dan kondisi wilayah, kemudahan mendapat sarana produksi, kemudahan memasarkan hasi dan harga produksinya.

Penelitian terdahulu tentang peran kelompok tani dapat digunakan sebagai bahan acuan untuk memilih faktor-faktor yang mempengaruhi peran kelompok tani dalam penerapan SRI dengan cara memilih faktor yang signifikan dan menambahkan dengan variabel lain yang dipandang potensial berpengaruh secara potensial. Faktor-faktor yang akan diteliti yaitu sikap petani, pengalaman petani, luas lahan petani, frekuensi petani menghadiri penyuluhan, pendidikan petani, peran penyuluh, dan peran ketua kelompok tani. 


\section{System Of Rice Intensification (SRI)}

Direktorat Jenderal Prasarana dan Sarana Pertanian pada tahun 2012 melaksanakan kegiatan untuk meningkatkan kemampuan teknis masyarakat tani melalui kegiatan Pelatihan dan Sekolah Lapangan System Of Rice Intensification (SRI) yaitu cara budidaya tanaman padi yang intensif dan efisien dengan proses manajemen sistem perakaran dengan berbasis pada pengelolaan tanah, tanaman dan air (Kementrian Pertanian 2012).

Komponen penting dalam penerapan SRI, yaitu meliputi(Wardana dkk., 2008):

1. Bibit dipindah lapang (transplantasi) lebih awal

Secara umum SRI menganjurkan untuk menanam bibit muda saat berumur 8-15 hari.

2. Bibit ditanam satu-satu daripada berumpun Hal ini dimaksudkan agar tanaman memiliki cukup ruang untuk menyebar dan memperdalam perakaran.

3. Jarak tanam lebar

SRI menganjurkan jarak tanam lebar dengan jarak minimal $25 \mathrm{~cm}$ x $25 \mathrm{~cm}$ agar akar tanaman tidak berkompetisi dan mempunyai cukup ruang untuk berkembang sehingga anakan maksimum dapat dicapai.

4. Kondisi tanah tetap lembab tapi tidak tergenang air

SRI menganjurkan teknik irigasi berselang agar tercipta kondisi perakaran yang teroksidasi, untuk meningkatkan kesuburan tanah dan mendapatkan akar tanaman yang panjang dan lebat.

5. Pendangiran

SRI menganjurkan 2-3 kali pendangiran dengan menggunakan gasrok atau landak, selain untuk membersihkan gulma, memperbaiki struktur tanah dan meningkatkan aerasi tanah.

6. Bahan organik (kompos)

SRI mengnjurkan pemakaian bahan organik (kompos) untuk memperbaiki struktur tanah agar padi dapat tumbuh baik dan hara tersuplai kepada tanaman secara baik.

\section{METODE PENELITIAN}

Metode dasar yang digunakan dalam penelitian ini adalah deskriptif. Menurut Nazir (2012) penelitian deskriptif adalah suatu metode dalam meneliti status sekelompok manusia, objek, set kondisi, sistem pemikiran, atau suatu kelas peristiwa yang terjadi pada masa sekarang.

Tujuan dari penelitian deskriptif adalah membuat deskripsi, gambaran atau lukisan secara sistematis, faktual dan akurat, mengenai faktafakta, sifat-sifat serta hubungan antar fenomena yang diselidiki. Hipotesis dari penelitian ini adalah:

1. Hipotesis pertama untuk mengetahui sejauh mana peran kelompok tani dalam penerapan SRI di Kecamatan Kalikajar Kabupaten Wonosobo adalah dengan menggunakan uji proporsi.

Pengujian hipotesis pertama:

a. Hipotesis yang digunakan adalah:

$\mathrm{H} 0: \mathrm{P} \leq 50 \%$

Ha: $\mathrm{P}>50 \%$

Dengan pengertian:

H0: diduga kurang dari atau sama dengan $50 \%$ petani menganggap kelompok tani memiliki peran tinggi terhadap penerapan SRI.

Ha: diduga lebih dari $50 \%$ petani menganggap kelompok tani memiliki peran tinggi terhadap penerapan SRI.

Statistik pengujian dihitung menggunakan rumus:

$$
\text { Zhit }=\frac{x / n-P o}{\sqrt{\frac{P o(1-P o)}{N}}}
$$

Keterangan:

$\mathrm{X}$ : jumlah petani sampel yang memiiki

peran tinggi terhadap penerapan SRI

$\mathrm{N}$ : jumlah keseluruhan petani sampel.

Po : koefisien keyakinan

b. Kriteria pengujian:

Z Hit $\leq \mathrm{Z}$ tabel : H0 diterima, maka Ha ditolak

Z Hit > Z tabel : H0 ditolak, maka $\mathrm{Ha}$ diterima

c. Penentuan "level of sigifican" digunakan tingkat kepercayaan $95 \%(\alpha=0,05)$ dengan $\mathrm{N}=60$. 
2. Pada hipotesis kedua untuk mengetahui faktor-faktor yang mempengaruhi peran kelompok tani dalam penerapan SRI di Kecamatan Kalikajar Kabupaten Wonosobo adalah dengan menggunakan analisis regresi linier berganda.

Pengujian hipotesis kedua:

a. Hipotesis yang digunakan:

H0: $\mathrm{b} 1=\mathrm{b} 2=\mathrm{b} 3=\mathrm{b} 4=\mathrm{b} 5=\mathrm{b} 6=\mathrm{b} 7$

Ha: $\mathrm{b} 1 \neq \mathrm{b} 2 \neq \mathrm{b} 3 \neq \mathrm{b} 4 \neq \mathrm{b} 5 \neq \mathrm{b} 6 \neq \mathrm{b} 7$

Pengujian analisis regresi linier berganda ini menggunakan program SPSS 16.0 for windows dengan metode backward dengan taraf signifikansi $5 \%$ atau 0,05 sehingga didapatkan persamaan berikut:

$$
\begin{aligned}
\mathrm{Y}= & \mathrm{A}+\mathrm{b} 1 \mathrm{X} 1+\mathrm{b} 2 \mathrm{X} 2+\mathrm{b} 3 \mathrm{X} 3+\mathrm{b} 4 \mathrm{X} 4 \\
& +\mathrm{b} 5 \mathrm{X} 5+\mathrm{b} 6 \mathrm{X} 6+\mathrm{b} 7 \mathrm{X} 7
\end{aligned}
$$

Keterangan:

$\begin{array}{ll}\text { Y } & \text { : Peran kelompok tani } \\ \text { A } & \text { : Nilai konstanta } \\ \text { b1,..b7 } & \text { : Koefisien regresi } \\ \text { X1 } & \text { : Pendidikan Petani } \\ \text { X2 } & \text { : Luas Lahan Petani } \\ \text { X3 } & \text { : Pengalaman Anggota } \\ \text { X4 } & \text { : Frekuensi Penyuluhan } \\ \text { X5 } & \text { : Sikap Anggota } \\ \text { X6 } & \text { : Peran Penyuluh } \\ \text { X7 } & \text { : Peran KEtua Kelompok Tani }\end{array}$

Kriteria pengujian:

Dengan menggunakan software SPSS 16.0 dapat dilakukan analisis sebagai berikut:

i. $R$ square atau koefisien determinasi menunjukan persen variabel dependen yang dapat diterangkan oleh variable independen

ii. Uji ANOVA atau $\mathrm{F}$ test jika nilai sig < $\alpha(0,05)$ maka variabel independen secara bersama-sama berpengaruh terhadap variabel dependen.

iii. Uji t, jika nilai $\operatorname{sig} \geq \alpha \rightarrow \mathrm{H} 0$ diterima maka Ha ditolak dan jika nilai sig $<\alpha$

$\checkmark$ H0 ditolak maka Ha diterima ( $\alpha$ $: 0,05)$

3. Pada hipotesis ketiga untuk mengetahui pengaruh peran kelompok tani terhadap penerapan SRI di Kecamatan Kalikajar Kabupaten Wonosobo digunakan analisis regresi linier sederhana.
Pengujian hipotesis kedua:

a. Hipotesis yang digunakan:

$\mathrm{H} 0: \mathrm{b} 1=0$

Ha: $\mathrm{b} 1 \neq 0$

Dengan pengertian:

H0: Tidak ada pengaruh antara peran kelompok tani terhadap penerapan SRI di Kecamatan Kalikajar Kabupaten Wonosobo.

Ha: Ada pengaruh antara peran kelompok tani terhadap penerapan SRI di Kecamatan Kalikajar Kabupaten Wonosobo.

b. Pengujian analisis regresi linier sederhana ini menggunakan program SPSS 16.0 for windows dengan metode enter dengan taraf signifikansi $5 \%$ atau 0,05 sehingga didapatkan persamaan berikut:

$\mathrm{Y}=\mathrm{A}+\mathrm{b} 1 \mathrm{X} 1$

Keterangan:

$\mathrm{Y}=$ Penerapan SRI

A = Nilai konstanta

$\mathrm{B}=$ Koefisien regresi

$\mathrm{X} 1$ = Peran kelompok tani

c. Kriteria pengujian:

Dengan menggunakan software SPSS 16.0 dapat dilakukan analisis sebagai berikut:

$i$. $R$ square atau koefisien determinasi menunjukan persen variabel dependen yang dapat diterangkan oleh variable independen.

ii. Uji ANOVA atau F test jika nilai sig < $\alpha(0,05)$ maka variabel independen secara bersama-sama berpengaruh terhadap variabel dependen.

iii. Uji t, jikanilai sig $\geq \alpha \rightarrow \mathrm{H} 0$ diterima maka Ha ditolak dan jika nilai sig $<\alpha$ $\square$ H0 ditolak maka Ha diterima ( $\alpha$ $: 0,05)$

\section{HASIL DAN PEMBAHASAN}

\section{A. Peran Kelompok Tani}

Kelompok tani pada dasarnya adalah organisasi non formal di pedesaan yang merupakan kumpulan dari petani atas dasar keserasian dan kebutuhan bersama. Kelompok tani adalah wadah bagi petani untuk berbagi pengetahuan, informasi, ketrerampilan di bidang pertanian. Melalui kelompok tani inilah inovasi 
baru mulai diperkenalkan dan diterapkan, karena pendekatan kelompok tani adalah pendekatan yang paling efisien dan efektif untuk saat ini dalam penyuluhan pertanian masa kini.

Kelompok tani memiliki fungsi utama sebagai tempat belajar guna meningkatkan pengetahuan, media kerjasama dalam kegiatan usahatani, unit produksi, dan unit usaha bagi petani. Dalam penelitian ini, peran kelompok tani dibagi menjadi tiga yaitu sebagai media belajar, media kerjasama, dan unit produksi. Peran kelompok tani dapat dilihat pada Tabel 1.1.

Berdasarkan Tabel 1.1. dapat diketahui bahwa peran kelompok tani mencapai skor 45,47 dari skor maksimal 63,00. Tingkat peran kelompok tani secara keseluruhan mencapai persentase yang cukup tinggi yaitu sebesar $72,17 \%$. Hal ini menunjukkan kelompok tani sering menjalankan perannya sebagai media belajar, media kerjasama, dan unit produksi. Kelompok tani dapat menjalankan perannya sebagai media belajar, media kerjasama, dan unit produksi karena sebagian besar petani mendapat pengetahuan dan keterampilan baru melalui kelompok tani. Melalui kelompok tani petani dapat meningkatkan kerjasama dan mudah memperoleh modal dan saprodi. Sebaran peran kelompok tani dapat dilihat pada Tabel 1.2.

Dari Tabel 1.2. dapat diketahui bahwa 41 petani responden atau sebanyak $68,33 \%$ petani menilai tingkat peran kelompok tani termasuk dalam kategori tinggi, dan 19 orang atau 31,67\% menilai peran kelompok dalam kategori sedang. Sebagian petani menilai kelompok tani telah menjalankan fungsinya dengan cukup baik untuk mendukung penerapan inovasi baru khususnya SRI.

\section{UJI PROPORSI}

Tinggi rendahnya peran kelompok tani juga dapat diketahui dengan melakukan uji proporsi yang bertujuan untuk mengetahui sejauh mana peran kelompok tani dalam penerapan SRI di Kecamatan Kalikajar. Diduga lebih dari 50\% petani menganggap kelompok tani memiliki peran tinggi terhadap penerapan SRI. Untuk membuktikan kebenaran dan hipotesis maka dilakukan perhitungan dengan langkah-langkah sebagai berikut:

a. Hipotesis:

$\mathrm{H} 0: \mathrm{P} \leq 50 \%$

Ha: $\mathrm{P}>50 \%$

Dengan pengertian:

H0: diduga kurang dari atau sama dengan $50 \%$ petani menganggap kelompok tani memiliki peran tinggi terhadap penerapan SRI.

Ha: diduga lebih dari $50 \%$ petani menganggap kelompok tani memiliki peran tinggi terhadap penerapan SRI.

b. Penentuan "level of sigifican" digunakan tingkat kepercayaan $95 \%(\alpha=0,05)$ dengan $\mathrm{N}=60$.

c. Pengujian Statistik

$$
\text { Zhit }=\frac{x / n-P o}{\sqrt{\frac{P o(1-P o)}{N}}}
$$

Tabel 1.1. Peran Kelompok Tani di Kecamatan Kalikajar

\begin{tabular}{|c|l|c|c|c|}
\hline No & \multicolumn{1}{|c|}{ Indikator } & Interval Skor & $\begin{array}{c}\text { Skor Rerata } \\
\text { Capaian }\end{array}$ & $\begin{array}{c}\text { Tingkat Peran } \\
(\%)\end{array}$ \\
\hline 1 & Media Belajar & $0-31$ & 24.40 & 78.71 \\
\hline 2 & Media Kerjasama & $0-22$ & 14.15 & 64.32 \\
\hline 3 & Unit Produksi & $0-10$ & 6.92 & 69.20 \\
\hline & Jumlah & $0-63$ & 45.47 & 72.17 \\
\hline
\end{tabular}

Sumber: Analisis Data Primer, 2013

Tabel 1.2. Sebaran Petani Berdasarkan Peran Kelompok Tani di Kecamatan Kalikajar

\begin{tabular}{|c|l|c|c|}
\hline No & \multicolumn{1}{|c|}{ Kategori Peran Kelompok Tani } & Jumlah (org) & Prosentase (\%) \\
\hline 1 & Rendah $(0-21)$ & 0 & 0.00 \\
\hline 2 & Sedang $(22-42)$ & 19 & 31.67 \\
\hline 3 & Tinggi $(43-63)$ & 41 & 68.33 \\
\hline & Jumlah & 60 & 100.00 \\
\hline
\end{tabular}

Sumber: Analisis Data Primer, 2013 


$$
\begin{aligned}
\text { Zhit } & =\frac{41 / 60-0.5}{\sqrt{\frac{0.5(1-0.5)}{60}}} \\
& =\frac{0.183}{0.064} \\
& =2.864
\end{aligned}
$$

d. Kriteria pengujian:

$\mathrm{Z}$ Hit $\leq \mathrm{Z}$ tabel : H0 diterima, maka Ha ditolak

Z Hit > Z tabel : H0 ditolak, maka Ha diterima

e. $\mathrm{Z}$ tabel $=-1.649$

2,864 > -1,649, z hitung lebih besar dari z tabel maka $\mathrm{H} 0$ ditolak dan Ha diterima. Jadi lebih dari $50 \%$ petani menganggap kelompok tani memiliki peran tinggi terhadap penerapan SRI.

Berdasarkan hasi perhitungan menggunakan uji proporsi, diperoleh $\mathrm{Z}$ hitung sebesar 2,846. Hasil uji proporsi lebih besar dari $\mathrm{Z}$ tabel yaitu -1,649. Hal ini menunjukkan lebih dari 50\% petani menganggap kelompok tani memiliki peran tinggi terhadap penerapan SRI. SRI adalah salah satu inovasi yang dikenalkan melalui sekolah lapang yang dilaksanakan kelompok tani. Oleh sebab itu penerapan SRI akan berhasil jika kelompok mampu menjalankan perannya dengan baik.

\section{Faktor-Faktor yang Mempengaruhi Peran Kelompok Tani dalam Penerapan SRI}

Tujuan kedua dalam penelitian ini adalah untuk mengetahui faktor-faktor yang mempengaruhi peran kelompok tani dalam penerapan SRI. Dalam hipotesis yang ke dua ini dilakukan analisis regresi linier berganda dengan menggunakan SPSS 16. Metode yang digunakan adalah backward.

Variabel dependen (Y) dalam pengujian analisis regresi berganda adalah peran kelompok tani dan variabel independen (X) yang meliputi tingkat pendidikan, luas lahan, pengalaman, frekuensi, sikap, peran penyuluh, dan peran ketua kelompok tani. Secara bertahap variabel-variabel yang tidak berpengaruh nyata dihilangkan sehingga terbentuk model dengan variabel yang signifikan pada model terakhir (model 6) yaitu sikap dan peran penyuluh. Hasil analisis regresi linier berganda model 6 dapat dilihat pada Tabel 1.3. Hasil analisis regresi linier bergandana pada Tabel 6.10. menyatakan bahwa nilai signifikansi sikap dan peran penyuluh lebih kecil dari taraf signifikansi $\alpha$ : 0,05 . Hal ini menunjukkan bahwa sikap dan peran penyuluh memiliki pengaruh nyata terhadap peran kelompok tani dalam penerapan SRI.

Berdasarkan hasil analisis regresi berganda pada Tabel 6.10. diperoleh persamaan regresi sebagai berikut:

$$
\mathrm{Y}=5,039+0,222 \mathrm{X} 4+0,401 \mathrm{X} 5
$$

Keterangan:

$\mathrm{Y}=$ Peran Kelompok Tani

$\mathrm{X} 4=$ Sikap

$\mathrm{X} 5$ = Peran Penyuluh

Dari persamaan regresi berganda diatas dapat dijelaskan sebagai berikut:

a. Adjusted $\mathrm{R}$ square mencapai 0,385

Tabel 1.3. Hasil Analisis Regresi Linier Berganda mengenai Faktor-Faktor yang diduga berpengaruh terhadap peran kelompok tani dalam penerapan SRI (Model6)

\begin{tabular}{|l|r|r|r|}
\hline \multicolumn{1}{|c|}{ Variabel } & \multicolumn{1}{c|}{$\begin{array}{c}\text { Koefisien } \\
\text { Regresi }\end{array}$} & \multicolumn{1}{c|}{ T hitung } & \multicolumn{1}{c|}{ Signifikansi } \\
\hline Sikap (X4) & 0.222 & 2.584 & $0.012^{*}$ \\
\hline Peran Penyuluh (X5) & 0.401 & 3.795 & $0.000^{*}$ \\
\hline Konstanta & 5.039 & & \\
\hline R & 0.637 & & \\
\hline R Square & 0.406 & & \\
\hline Ajusted R Square & 0.385 & & \\
\hline F hitung & 19.458 & & \\
\hline F tabel & 3.158 & & \\
\hline Kele & & & \\
\hline
\end{tabular}

Keterangan: $*$ ) signifikasi pada taraf 5\%

Sumber: Analisis Data Primer, 2013 
menunjukkan bahwa sebesar 38,50\% variabel peran kelompok tani dapat dijelaskan oleh variabel sikap dan peran penyuluh. Sedangkan $61,50 \%$ sisanya dijelaskan oleh variabel lain diluar model tersebut.

b. Berdasarkan Tabel 6.10. nilai $\mathrm{F}$ hitung adalah 19,458 dan $\mathrm{F}$ tabel adalah 3,158. $\mathrm{F}$ hitung > F tabel menunjukkan bahwa variabel independen yaitu sikap dan peran penyuluh secara bersama sama berpengaruh nyata terhadap peran kelompok tani dalam penerapan SRI (variabel dependen)

Berikut ini akan dibahas hasil uji hipotesis masing-masing faktor yang berpengaruh nyata terhadap peran kelompok tani dalam penerapan SRI yang merupakan hasil analisis regresi berganda metode backward (model 6).

\section{Sikap}

Hasil analisis regresi linier berganda pada model 6 dapat dilihat bahwa nilai signifikansi sikap sebesar 0,012 lebih kecil dari taraf signikansi $\alpha$ : 0,05 . Variabel sikap memiliki $t$ hitung 2,584 dan $\mathrm{t}$ tabel sebesar 2,001. Hal ini menujukkan bahwa Ha diterima karena t hitung > $\mathrm{t}$ tabel. Dengan demikian variabel sikap berpengaruh nyata terhadap peran kelompok tani dalam penerapan SRI. Berdasarkan hasil analisis regresi linier berganda pada Tabel 6.10. diperoleh persamaan regresi sebagai berikut:

$$
\mathrm{Y}=5,039+0,222 \mathrm{X} 4
$$

Keterangan:

$$
\mathrm{Y}=\text { Peran Kelompok Tani }
$$$$
\mathrm{X} 4 \text { = Sikap }
$$

Persamaan regresi linier pengaruh sikap terhadap peran kelompok tani dapat disajikan dalam Gambar 6.1.

Dari Gambar 6.1. dapat diketahui bahwa variabel sikap berpengaruh positif $(+)$ terhadap peran kelompok tani. Pengaruh positif dapat diartikan penambahan nilai variabel sikap akan menaikkan akan menaikkan peran kelompok tani. Nilai koefisien regresi sebesar 0,222 artinya apabila variabel sikap meningkat satu satuan maka peran kelompok tani akan meningkat sebanyak 0,222. Nilai konstanta sebesar 5,039 artinya jika variabel sikap bernilai nol satuan
$(\mathrm{X}=0)$ maka nilai peran kelompok tani adalah 5,039. Dengan demikian hipotesis 2a diterima karena semakin positif sikap petani maka semakin tinggi peran kelompok tani. Sikap petani yang mendukung akan cenderung lebih terbuka dalam menerima informasi, bekerjasama, menerapkan inovasi yang disampaikan penyuluh, dan akhirnya dapat meningkatkan peran kelompok tani.

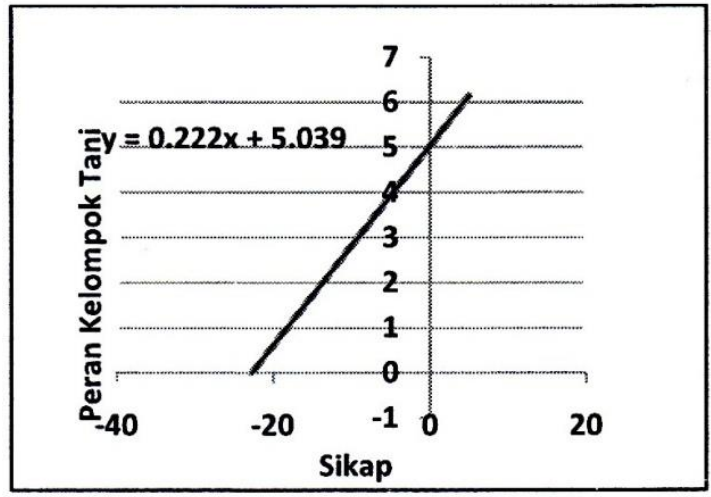

Gambar 6.1. Grafik Pengaruh Sikap terhadap Peran Kelompok Tani

\section{Peran Penyuluh}

Hasil analisis regresi linier berganda pada model 6 dapat dilihat bahwa nilai signifikansi peran penyuluh sebesar 0,000 lebih kecil dari taraf signikansi $\alpha$ : 0,05 . Variabel peran penyuuh memiliki thitung 3,795 dan $\mathrm{t}$ tabel sebesar 2,001. Hal ini menujukkan bahwa Ha diterima karena $t$ hitung > t tabel. Dengan demikian variabel peran penyuluh berpengaruh nyata terhadap peran kelompok tani dalam penerapan SRI. Berdasarkan hasil analisis regresi linier berganda pada Tabel 6.10 diperoleh persamaan regresi sebagai berikut:

$$
\mathrm{Y}=5,039+0,401 \mathrm{X} 5
$$

Keterangan:

$\mathrm{Y}=$ Peran Kelompok Tani

$\mathrm{X} 5$ = Peran penyuluh

Persamaan regresi linier pengaruh peran penyuluh terhadap peran kelompok tani dapat disajikan dalam Gambar 6.2.

Dari Gambar 6.2. dapat diketahui bahwa variabel peran penyuluh berpengaruh positif $(+)$ terhadap peran kelompok tani. Pengaruh positif dapat diartikan penambahan nilai variabel peran penyuluh akan menaikkan peran kelompok tani. 


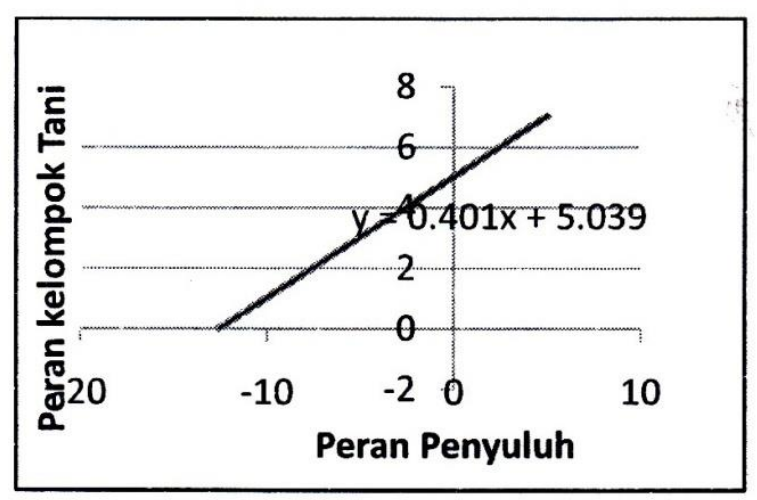

Gambar 6.2. Grafik Pengaruh Peran Penyuluh terhadap Peran Kelompok Tani

Nilai koefisien regresi sebesar 0,401 artinya apabila variabel peran penyuluh meningkat satu satuan maka peran kelompok tani akan meningkat sebanyak 0,401. Nilai konstanta sebesar 5,039 memiliki arti apabila tidak ada pengaruh dari peran penyuluh $(X=0)$ maka nilai peran kelompok tani sebesar 5,039. Dengan demikian hipotesis diterima karena semakin tinggi peran penyuluh maka semakin tinggi peran kelompok tani. Penyuluh yang mampu menjalankan perannya mendampingi kelompok tani akan menggerakkan petani anggota untuk berperan aktif dalam kelompok dan menerapkan inovasi yang disampaikan penyuluh yang akhirnya dapat meningkatkan peran kelompok tani.

\section{PENERAPAN SRI}

Penelitian ini mengelompokkan penerapan SRI dalam tiga kategori yaitu rendah, sedang, dan tinggi. Sebaran Petani berdasarkan penerapan SRI dapat di lihat pada Tabel 6.12. sebab sebagian besar telah menerapkan teknologi sesuai anjuran.

\section{E. PENGARUH PERAN KELOMPOK TANI TERHADAP PENERAPAN SRI}

Dalam penelitian ini diduga peran kelompok tani berpengaruh positif terhadap penerapan SRI. Analisis yang digunakan adalah analisis regresi linier sederhana dengan metode enter, peran kelompok tani sebagai variabel independen, dan penerapan SRI sebagai variabel dependen. Hasil analisis yang diperoleh dari uji linier sederhana dapat dilihat pada Tabel 6.13.

Berdasarkan Tabel 6.13. dapat diketahui bahwa variabel peran kelompok tani mempunyai nilai signifikansi sebesar 0,000 lebih kecil dari taraf signikansi $\alpha$ : 0,05 . Hal ini menunjukan bahwa peran kelompok tani berpengaruh nyata dalam penerapan SRI. Dari Tabel 6.13. dapat dijelaskan sebagai berikut:

a. Nilai koefisien determinasi (R Square) sebesar 0,340 atau 34\% variabel penerapan SRI dapat dijelaskan oleh variabel peran kelompok tani sedangkan 66\% sisanya dijelaskan oleh faktor-faktor lain di luar model.

b. Uji ANOVA atau F test dilakukan untuk mengetahui apakah variabel independen secara bersama-sama berpengaruh terhadap variabel dependen. Pengambilan keputusannya yaitu jika F hitung lebih dari $F$ tabel maka variabel independen secara bersama-sama berpengaruh terhadap variabel dependen begitupun sebaiknya. Dalam penelitian ini, nilai $\mathrm{F}$ hitung sebesar

Tabel 6.12. Sebaran Petani Berdasarkan Penerapan SRI di Kecamatan Kalikajar

\begin{tabular}{|c|l|c|c|}
\hline No & \multicolumn{1}{|c|}{ Kategori Peran Kelompok Tani } & Jumlah (org) & Prosentase (\%) \\
\hline 1 & Rendah $(0-21)$ & 1 & 1.67 \\
\hline 2 & Sedang $(22-42)$ & 31 & 51.67 \\
\hline 3 & Tinggi $(43-63)$ & 28 & 46.67 \\
\hline & Jumlah & 60 & 100.00 \\
\hline
\end{tabular}

Sumber: Analisis Data Primer, 2013

Berdasarkan Tabel 6.12. dapat diketahui bahwa 28 petani $(46,67 \%)$ menilai penerapan SRI dalam kategori tinggi, 31 petani $(51,67 \%)$ dalam kategori sedang, dan 1 petani $(1,67 \%)$ dalam kategori rendah. Hal ini berarti kesadaran petani untuk meningkatkan usahataninya cukup tinggi,
29,899 dan $F$ tabel 4,006. Hal ini menunjukan variabel peran kelompok tani secara bersama-sama berpengaruh nyata terhadap penerapan SRI.

c. Uji $\mathrm{t}$ dilakukan untuk mengetahui ada tidaknya pengaruh masing-masing variabel 
independen terhadap variabel dependen. Pengambilan keputusannya adalah jika $t$ hitung lebih dari $\mathrm{t}$ tabel maka maka masing-masing variabel independen berpengaruh nyata terhadap variabel dependen, dan jika t hitung kurang dari atau sama dengan $t$ tabel maka masingmasing variabel independen tidak berpengaruh nyata terhadap variabel dependen. Dalam penelitian ini nilai $t$ hitung adalah 5,648 lebih besar dari t tabel 2,001. Dapat disimpulkan bahwa masing masing variabel peran kelompok tani berpengaruh nyata terhadap penerapan SRI.

Berdasarkan hasil analisis regresi linier sederhana pada Tabel 6.3. maka dapat diperoleh persamaan regresi sebagai berikut:

$$
\mathrm{Y}=2,368+0,981 \mathrm{X}
$$

Keterangan:

$\mathrm{Y}=$ Penerapan SRI

$\mathrm{X}=$ Peran Kelompok Tani
Persamaan regresi pengaruh peran kelompok tani terhadap penerapan SRI dapat disajikan dalam Gambar 6.3.

Dari Gambar 6.3. dapat diketahui bahwa variabel peran kelompok tani berpengaruh positif terhadap penerapan SRI. Pengaruh positif dapat diartikan setiap penambahan nilai variabel peran kelompok tani akan menaikkan tingkat penerapan SRI. Koefisien regresi variabel peran kelompok tani sebesar 0,981 yang berarti apabila peran kelompok tani meningkat satu satuan maka tingkat penerapan SRI akan meningkat sebanyak 0,981 . Berdasarkan persamaan regresi nilai konstanta sebesar 2,368 yang artinya apabila tidak ada pengaruh dari peran kelompok tani $(X=0)$ maka nilai penerapan SRI sebesar 2,368. Dengan demikian dapat disimpulkan hipotesis diterima yaitu ada pengaruh antara peran kelompok tani terhadap penerapan SRI di Kecamatan Kalikajar.

Tabel 6.13. Hasil Analisis Regresi Linier Sederhana Mengenai Pengaruh Peran Kelompok Tani terhadap Penerapan SRI

\begin{tabular}{|l|r|r|r|}
\hline \multicolumn{1}{|c|}{ Variabel } & \multicolumn{1}{c|}{$\begin{array}{c}\text { Koefisien } \\
\text { Regresi }\end{array}$} & \multicolumn{1}{c|}{ T hitung } & \multicolumn{1}{c|}{ Signifikansi } \\
\hline (Konstanta) & 2.368 & 0.287 & 0.775 \\
\hline Peran Kelompok Tani & 0.981 & 5.648 & $0.000^{*}$ \\
\hline R & 0.583 & & \\
\hline R Square & 0.340 & & \\
\hline Adjusted R Square & 0.329 & & \\
\hline F hitung & 29.899 & & \\
\hline F tabel & 4.006 & & \\
\hline
\end{tabular}

Keterangan: *) signifikasi pada taraf 5\%

Sumber: Analisis Data Primer, 2013

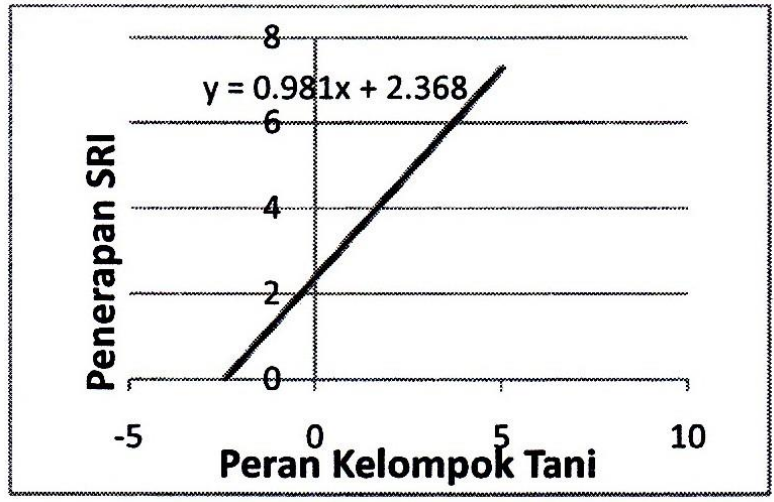

Gambar 6.3. Grafik Pengaruh Peran Kelompok Tani terhadap Penerapan SRI

\section{F. KESIMPULAN}

1. Sebesar $68,33 \%$ petani di Kecamatan Kalikajar Kabupaten Wonosobo menilai kelompok tani memiliki peran tinggi terhadap penerapan SRI.

2. Peran kelompok tani secara keseluruhan mencapai persentase sebesar $72,17 \%$ yang berarti kelompok tani sering menjalankan perannya sebagai media belajar, media kerjasama, dan unit produksi di Kecamatan Kalikajar Kabupaten Wonosobo

3. Faktor-faktor yang berpengaruh nyata terhadap peran kelompok tani dalam 
penerapan SRI yaitu sikap dan peran penyuluh.

a. Semakin positif sikap petani maka semakin tinggi peran kelompok tani dalam penerapan SRI

b. Semakin tinggi peran penyuluh maka semakin tinggi peran kelompok tani dalam penerapan SRI.

4. Faktor-faktor yang tidak berpengaruh nyata terhadap peran kelompok tani dalam penerapan SRI ialah pendidikan petani, luas lahan, pengalaman, frekuensi kehadiran, dan peran ketua kelompok tani.

5. Tingkat penerapan SRI di Kecamatan Kalikajar Kabupaten Wonosobo mencapai persentase sebesar $67,12 \%$. Hal ini berarti petani di Kecamatan Kalikajar sering menjalankan prinsip-prinsip dalam SRI yang dianjurkan.

6. Peran Kelompok tani berpengaruh positif terhadap penerapan SRI di Kecamatan Kalikajar Kabupaten Wonosobo, artinya jika peran kelompok tani semakin tinggi maka penerapan SRI di Kecamatan Kalikajar akan semakin tinggi pula.

\section{DAFTAR PUSTAKA}

Dwiyanto, D. 2010. Pengaruh Peran Kelompok Tani terhadap Motivasi Petani dalam Budidaya Padi Sawah di Kecamatan Sragen Kabupaten Sragen. Universitas Gadjah Mada. Skripsi.

Ishak, A. dan Afrizon. 2011. Persepsi dan Tingkat Adopsi Petani Padi Terhadap PenerapanSystem Of Rice Intensification (SRI) Di Desa Bukit Peninjauan I,Kecamatan Sukaraja, Kabupaten Seluma.Informatika Pertanian, Vol. 20 No.2, Desember 2011 : 76 - 80.

Kementrian pertanian. 2012. Konsep Pedoman Teknis Pengembangan System of RiceIntensification. <http://www.deptan.go. $\mathrm{id} /$ pedum2012/PSP/4.0.\%20PEDUM\%20S RI\%202012.pdf>. Diakses 09 September 2012.

Wardana, I. P., Sumedi, dan I. S. Anugrah. 2008. Gagasan dan Implementasi System Rice of Intensification (SRI) dalam Kegiatan Budidaya Padi Ekologis (BPE). Analisis Kebijakan Pertanian 6 (1): 75-99.
Widyaningrum. 2001. Perilaku Petani dalam Komunikasi Alih Teknologi Budidaya. Universitas Gadjah Mada. Skripsi.

Deptan. 2007. Peraturan Menteri Pertanian No: 273 / KPTS / OT.160 / 4/ 2007 tentang Pedoman Kelembagaan Petani. Departemen Pertanian. Jakarta. 